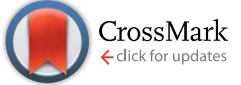

Cite this: J. Mater. Chem. A, 2015, 3, 4722

Received 10th December 2014 Accepted 15th January 2015

DOI: $10.1039 / \mathrm{c} 4 \mathrm{ta0} 6763 \mathrm{k}$

www.rsc.org/MaterialsA

\section{Polydopamine-based synthesis of a zeolite imidazolate framework ZIF-100 membrane with high $\mathrm{H}_{2} / \mathrm{CO}_{2}$ selectivity}

\author{
Nanyi Wang, ${ }^{* a}$ Yi Liu, ${ }^{a}$ Zhiwei Qiao, ${ }^{b}$ Lisa Diestel, ${ }^{a}$ Jian Zhou, ${ }^{b}$ Aisheng Huang ${ }^{\star c}$ \\ and Jürgen Caro ${ }^{a}$
}

A highly permselective ZIF-100 molecular sieve membrane has been prepared on a polydopamine (PDA)modified support. Attributed to the formation of strong covalent and non-covalent bonds between PDA and ZIF-100, the ZIF-100 nutrients are attracted and bound to the support surface, thus promoting the growth of well-intergrown and phase-pure ZIF-100 membranes. The developed ZIF-100 membranes show high $\mathrm{H}_{2} / \mathrm{CO}_{2}$ selectivity due to the outstanding $\mathrm{CO}_{2}$ adsorption capacity of ZIF-100.

\section{Introduction}

The growing demand for energy and environmental issues has promoted the concept of "hydrogen economy". ${ }^{1}$ Currently, up to $90 \%$ of hydrogen is produced by steam-methane reforming (SMR) followed by the water-gas shift (WGS). Before it can be used in fuel cells, $\mathrm{H}_{2}$ has to be purified from the SMR gas mixture which mainly contains $\mathrm{CO}_{2} \cdot{ }^{2}$ Moreover, $\mathrm{H}_{2}$-selective membranes are also desired in the pre-combustion technology of $\mathrm{CO}_{2}$ sequestration. ${ }^{3}$ Compared with traditional separation methods like pressure swing adsorption (PSA) and cryogenic distillation, membrane-based separation techniques have attracted significant attention due to lower energy consumption and investment cost. $^{4}$ In the recent 20 years, inorganic membranes such as zeolite membranes, ${ }^{5}$ Pd-based membranes, ${ }^{6,7}$ amorphous microporous silica membranes ${ }^{8}$ and carbon membranes ${ }^{9}$ have been developed for the separation of $\mathrm{H}_{2}$ from $\mathrm{CO}_{2}$.

Recent efforts have been devoted to the fabrication of supported metal-organic framework (MOF) membranes due to their highly diversified structures and specific adsorption affinities. ${ }^{10-17}$ In particular, great attention has been paid to zeolite imidazolate framework (ZIF) membranes since 2009 because of their relatively high stability and tunable pore size. ${ }^{18,19}$ So far, a series of ZIF membranes with small pore sizes, including ZIF-7 $(0.30 \mathrm{~nm}),{ }^{\mathbf{2 0}} \mathrm{ZIF}-22(0.30 \mathrm{~nm}),{ }^{21} \mathrm{ZIF}-8$

${ }^{a}$ Institute of Physical Chemistry and Electrochemistry, Leibniz University of Hannover, Callinstrasse 22, 30167 Hannover, Germany.E-mail: nanyi.wang@pci.uni-hannover. de

${ }^{b}$ School of Chemistry and Chemical Engineering, Guangdong Provincial Key Lab for Green Chemical Product Technology, South China University of Technology, Guangzhou 510640, China

'Institute of New Energy Technology, Ningbo Institute of Material Technology and Engineering, CAS, 1219 Zhongguan Road, 315201 Ningbo, P. R. China. E-mail: huangaisheng@nimte.ac.cn
$(0.34 \mathrm{~nm}),{ }^{22-24}$ ZIF-90 (0.35 nm $)^{25-27}$ and ZIF-95 (0.37 nm) ${ }^{28}$ were successively developed for gas separation. Despite much progress in the development of $\mathrm{H}_{2}$-selective $\mathrm{ZIF}$ membranes, the development of thermally stable ZIF membranes with a high $\mathrm{H}_{2} / \mathrm{CO}_{2}$ selectivity is still desired.

Yaghi and co-workers have developed a novel ZIF-100 structure with the composition $\mathrm{Zn}_{20}(\mathrm{cbIM})_{39}(\mathrm{OH})$ through the reaction of $\mathrm{Zn}\left(\mathrm{O}_{3} \mathrm{SCF}_{3}\right)_{2}$ with 5-chlorobenzimidazole (cbIM). ${ }^{29} \mathrm{ZIF}$ 100 was found to have a rather complex structure. The unit cell of ZIF-100 has a MOZ topology, which is constructed from 7524 atoms. This MOZ cage has a large inner sphere with a diameter of $35.6 \AA$ and a constricted window aperture of only $3.35 \AA$. ZIF-100 shows a high affinity and capacity to $\mathrm{CO}_{2}$, which results in an outstanding $\mathrm{CO}_{2}$ uptake. ${ }^{29}$ It is reported that ZIF-100 not only has high $\mathrm{CO}_{2}$ capacity, but also a high thermal stability up to $500{ }^{\circ} \mathrm{C} .{ }^{29}$ It is worth mentioning that the high $\mathrm{CO}_{2}$ adsorption capacity as found for MOFs with accessible metal ions like MIL-53 $3^{30}$ or MOF- $74^{31}$ is not common for ZIFs. However, the adsorption affinity of ZIF-100 for $\mathrm{CO}_{2}$ outperforms that of ZIF-95 and BPL carbon, ${ }^{32}$ which is widely used in industry for gas separation.

Although there have been a few studies of ZIF-100 powders on gas adsorption, ${ }^{33}$ to date no ZIF-100 membrane with gas separation performance has been reported. In this study, we report the synthesis of a dense ZIF-100 membrane by covalent modification of the substrate surface using polydopamine (PDA), as shown in Fig. 1. During this pre-modification process, dopamine can easily polymerize into PDA, and stick on different kinds of organic and inorganic material surfaces. ${ }^{34}$ Then the PDA-modified surface can be used as a versatile platform for further reactions. ${ }^{35-37}$ Recently, PDA-based synthesis of ZIF-8 and zeolite LTA membranes has been developed to improve their gas separation performance and reproducibility. ${ }^{38-40}$ It can be expected, therefore, that ZIF-100 membranes prepared on 


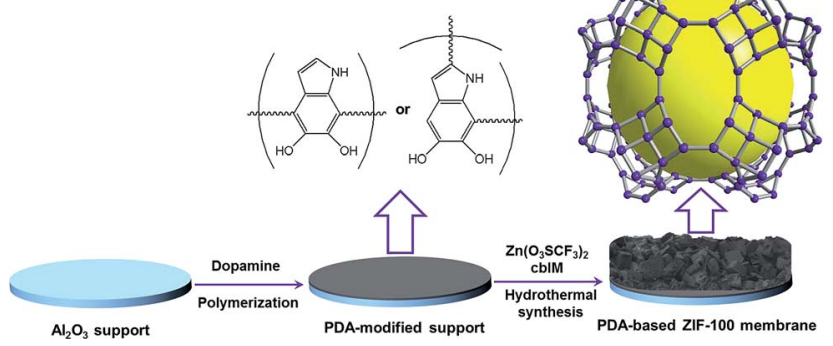

Fig. 1 Schematic diagram of the synthesis of ZIF-100 membranes on a polydopamine-modified $\mathrm{Al}_{2} \mathrm{O}_{3}$ support.

PDA-functionalized supports will show higher gas separation performances and reproducibility of membrane preparation.

\section{Experimental}

\subsection{Materials}

Chemicals were used as received: zinc trifluoromethane-sulfonate (98\%, Aldrich), 5-chlorobenzimidazole (cbIM, 98\%, Abcr), $N, N$-dimethylformamide (DMF, water $<50 \mathrm{ppm}$, Acros), dopamine hydrochloride (Sigma), and tris(hydroxymethyl)aminomethane (Tris-HCl, $\geq 99.8 \%$, Sigma-Aldrich). Porous $\alpha-\mathrm{Al}_{2} \mathrm{O}_{3}$ disks (Fraunhofer Institute IKTS, former HITK/Inocermic, Hermsdorf, Germany: $18 \mathrm{~mm}$ in diameter, $1.0 \mathrm{~mm}$ in thickness, $70 \mathrm{~nm}$ particles in the top layer) were used as supports.

\subsection{Polydopamine (PDA) modification of the support surface}

The PDA modification of the support surface was done according to a previous procedure.$^{38-40}$ Dopamine hydrochloride $\left(2 \mathrm{mg} \mathrm{mL}{ }^{-1}\right.$ ) was dissolved in $10 \mathrm{mM}$ Tris-HCl (pH 8.5) in an open air vessel (diameter: $180 \mathrm{~mm}$ ). And then the porous $\alpha-\mathrm{Al}_{2} \mathrm{O}_{3}$ disks were placed facing up into the dopamine solution $(50 \mathrm{~mL})$. A magnetic stirrer was placed in the middle of the vessel surrounded in a satellite-shape by 6 support discs. The solution was then stirred for $20 \mathrm{~h}$ at room temperature, leading to the polymerization of dopamine into PDA on the alumina support surface. The oxygen needed for the dopamine polymerization dissolved from air.

\subsection{Synthesis of the ZIF-100 membrane}

The ZIF-100 membrane was prepared by a solvothermal reaction of trifluoromethanesulfonate and cbIM in DMF according to a previous report. ${ }^{29}$ The PDA-modified or PDA-free $\alpha-\mathrm{Al}_{2} \mathrm{O}_{3}$ supports were placed horizontally in a Teflon-lined stainless steel autoclave which was filled with $15 \mathrm{~mL}$ synthesis solution, and heated at $120{ }^{\circ} \mathrm{C}$ in an air oven for $48 \mathrm{~h}$. After the solvothermal reaction, the ZIF-100 membranes were washed with DMF several times, and then dried in air at $110{ }^{\circ} \mathrm{C}$ overnight.

\subsection{Characterization of the ZIF-100 membrane}

The X-ray diffraction (XRD) patterns were recorded at room temperature under ambient conditions with an X-ray diffractometer (D8 Advance, Bruker-AXS, with $\mathrm{Cu}-\mathrm{K} \alpha$ radiation at $40 \mathrm{kV}$ and $40 \mathrm{~mA}$ ). The morphology and thickness of the ZIF-100 membranes were characterized by scanning electron microscopy (SEM) at $2 \mathrm{keV}$ and $10 \mu \mathrm{A}$ by using a JEOL Jeol-JSM$6700 \mathrm{~F}$ with a cold field emission gun. By using the same SEM microscope the chemical composition of the cross-section of ZIF-100 was characterized by energy-dispersive X-ray spectroscopy (EDXS) at $20 \mathrm{kV}$ and $20 \mu \mathrm{A}$. The chemical composition of the cross-section of the ZIF-100 layer was characterized by energy-dispersive X-ray spectroscopy (EDXS) using the same SEM microscope at $20 \mathrm{kV}$ and $20 \mu \mathrm{A}$.

\subsection{Simulation models and methods}

The Grand Canonical Monte Carlo (GCMC) simulation method in RASPA package ${ }^{41}$ was used to calculate the $\mathrm{H}_{2} / \mathrm{CO}_{2}$ mixed gas adsorption in ZIF-100. In the GCMC ensemble, the chemical potential, the volume, and the temperature were kept fixed as in the adsorption experiments. The chemical potential was related to the system pressure by the Peng-Robinson equation of state. In this work, the structure of ZIF-100 was constructed from the experimental single-crystal X-ray diffraction data. ${ }^{29}$ The standard 12-6 Lennard-Jones ( $\mathrm{LJ}$ ) potential was used to model the dispersive and repulsive interatomic interactions. The LorentzBerthelot mixing rules were employed to calculate gas/framework parameters. The LJ parameters of the ZIF-100 atoms were obtained from the Dreiding force field, ${ }^{42}$ and if not available in Dreiding, from the Universal Force Field. ${ }^{43}$ The partial charges of the ZIF-100 atoms were estimated using the CHELPG method $^{44}$ and the density functional theory (DFT) calculation using the B3LYP method ${ }^{45,46}$ and the LANL2DZ basis set. A united-atom model was used for $\mathrm{CH}_{4}$ with the $\mathrm{LJ}$ parameters from the TraPPE force field. ${ }^{47} \mathrm{~N}_{2}$ was mimicked by two-site models with a bond length of $1.10 \AA^{48}$ Partial charges and LJ parameters for $\mathrm{CO}_{2}$ were taken from the TraPPE force field. The electrostatic interactions for adsorbent-adsorbate and adsorbate-adsorbate were calculated by the Ewald summation technique. ${ }^{49}$

\subsection{Permeation of single gas and separation of mixed gases}

For the single and mixed gas permeation, every ZIF-100 membrane was sealed in a permeation cell with silicone O-rings. In our Wicke-Kallenbach permeation cell, we worked with feed and sweep gases at 1 bar. A calibrated gas chromatograph (HP6890) was used to detect the gas concentrations. The fluxes of both the feed and sweep gases were controlled by mass flow controllers. The flow rate on the feed side was kept

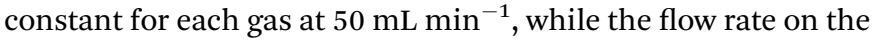

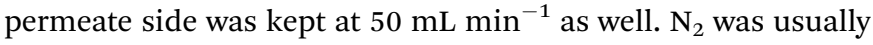
used as the sweep gas, except for the measurement of $\mathrm{N}_{2}$ permeance where $\mathrm{CH}_{4}$ was used as the sweep gas instead.

The permeance $P$ is obtained by the division of the flux by the transmembrane pressure difference, and the separation factor $\alpha_{i, j}$ of a binary mixture permeation is defined as the quotient of the molar ratios of the components $(i, j)$ in the permeate, divided by the quotient of the molar ratio of the components $(i, j)$ in the retentate. Since less than $1 \%$ of the feed gas can pass 
through the membrane, the retentate composition is de facto identical to the feed composition.

To prove the feasibility of the Wicke-Kallenbach technique, the membranes were also tested under pressure difference. In this case, the pressure on the feed side was 4 bar ( 2 bar partial pressure of the binary mixture), while the pressure on the permeate side was 1 bar.

The gas chromatograph (GC) was calibrated every week anew with standard gas mixtures. The accuracy of the GC analysis of our $\mathrm{H}_{2} / \mathrm{CO}_{2}$ mixture using TCD detection is about $\pm 5 \mathrm{vol} \%$. Before gas permeation, the ZIF-100 membranes were activated at $100{ }^{\circ} \mathrm{C}$ with a heating rate of $0.2{ }^{\circ} \mathrm{C} \min ^{-1}$ by using an equimolar $\mathrm{H}_{2} / \mathrm{CO}_{2}$ mixture in the Wicke-Kallenbach permeation apparatus. All permeation data were collected in the steady state of permeation after $12 \mathrm{~h}$ equilibration time.

\section{Results and discussion}

\subsection{Simulation study of gas adsorption isotherms of ZIF-100}

The mixed gas adsorption isotherms in ZIF-100 were examined by molecular simulation. The adsorption of an equimolar $\mathrm{H}_{2}$ / $\mathrm{CO}_{2}$ mixture in the pore structure of the ZIF-100 cage at $25{ }^{\circ} \mathrm{C}$ and 1 bar is shown as a snapshot in Fig. 2 . It can be clearly seen that a huge number of $\mathrm{CO}_{2}$ molecules are adsorbed in the pores of ZIF-100, while only a few $\mathrm{H}_{2}$ molecules are found. The simulation results of the gas adsorption isotherms of $\mathrm{H}_{2}, \mathrm{CO}_{2}$, $\mathrm{CH}_{4}$ and $\mathrm{N}_{2}$ at $25^{\circ} \mathrm{C}$ are compared to the available experimental data $^{29}$ in the pressure range from 10 to 750 Torr in Fig. 3. As shown in Fig. 3, the simulated isotherms of different gases coincide well with the measured ones in the whole pressure range. The adsorption of $\mathrm{CO}_{2}$ exceeds by far the adsorption of the other gases. The simulated adsorption isotherms of an equimolar $\mathrm{H}_{2} / \mathrm{CO}_{2}$ mixture at $25{ }^{\circ} \mathrm{C}$ are shown in Fig. 4 as a

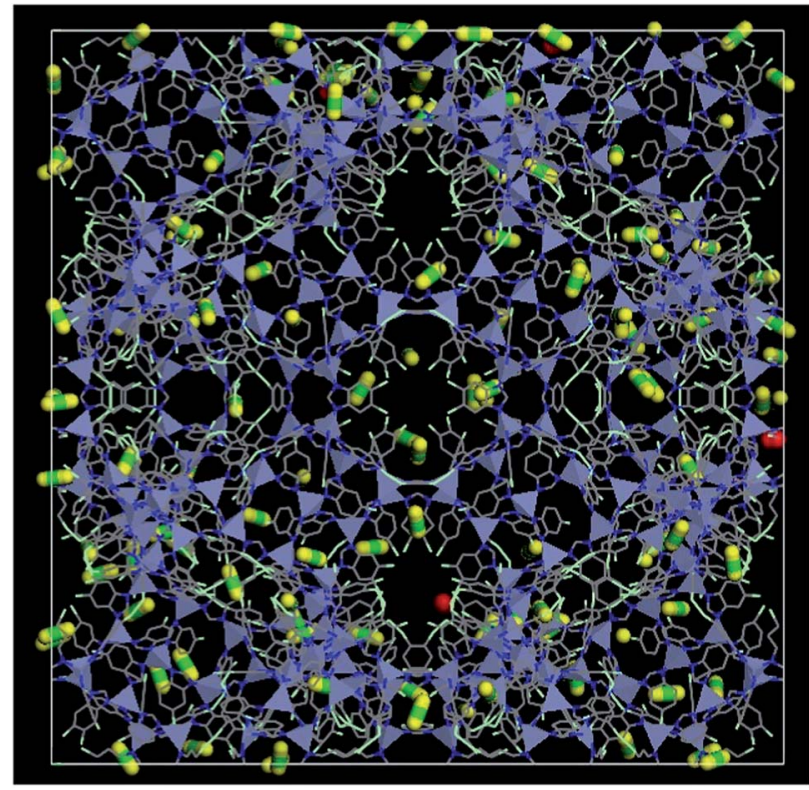

Fig. 2 Snapshot of adsorption of an equimolar $\mathrm{H}_{2} / \mathrm{CO}_{2}$ mixture in ZIF100 pores at $25^{\circ} \mathrm{C}$ and 1 bar with $\mathrm{CO}_{2}$ in yellow-green and $\mathrm{H}_{2}$ in red.

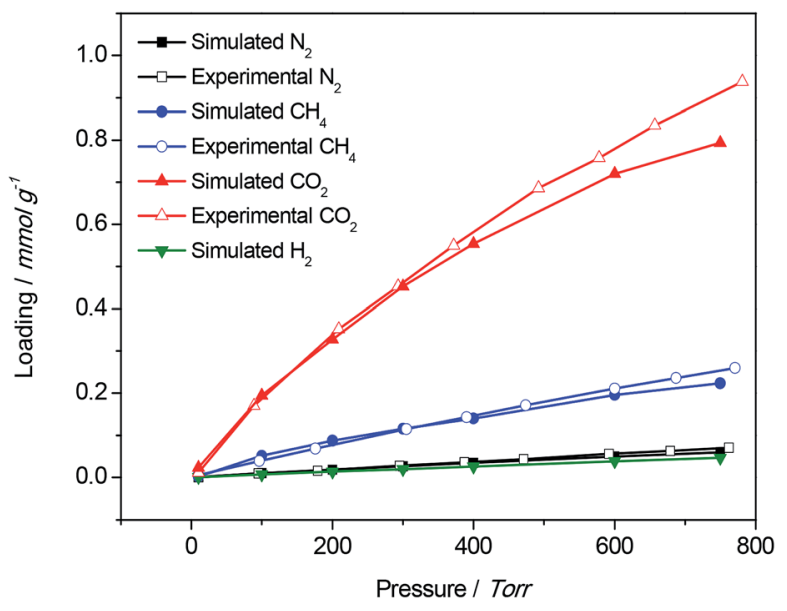

Fig. 3 Simulated single component adsorption isotherms of $\mathrm{H}_{2}, \mathrm{CO}_{2}$, $\mathrm{CH}_{4}$ and $\mathrm{N}_{2}$ at $25{ }^{\circ} \mathrm{C}$ in the pressure range from 10 to 750 Torr compared with the measured data. ${ }^{29}$

function of the total pressure. As shown in Fig. 4, $\mathrm{CO}_{2}$ is predominantly adsorbed over $\mathrm{H}_{2}$ in ZIF-100 in the whole pressure range due to the much stronger interaction between $\mathrm{CO}_{2}$ and ZIF-100. As a result, the simulation study of the gas adsorption isotherm in ZIF-100 is in good accordance with the experimental data, and the experimentally found strong adsorption affinity of ZIF-100 to $\mathrm{CO}_{2}$ was confirmed by the simulation.

\subsection{Synthesis of the ZIF-100 membrane}

We first tried to grow a ZIF-100 layer simply by in situ hydrothermal synthesis on an unmodified $\alpha$-alumina support, as shown in Fig. 5(a). However, it turned out to be extremely difficult to form a continuous ZIF-100 layer directly on the support due to the poor heterogeneous nucleation of ZIF-100 crystals on the $\alpha$-alumina support surface. Our recent study indicated that pre-modification of the support surface with PDA

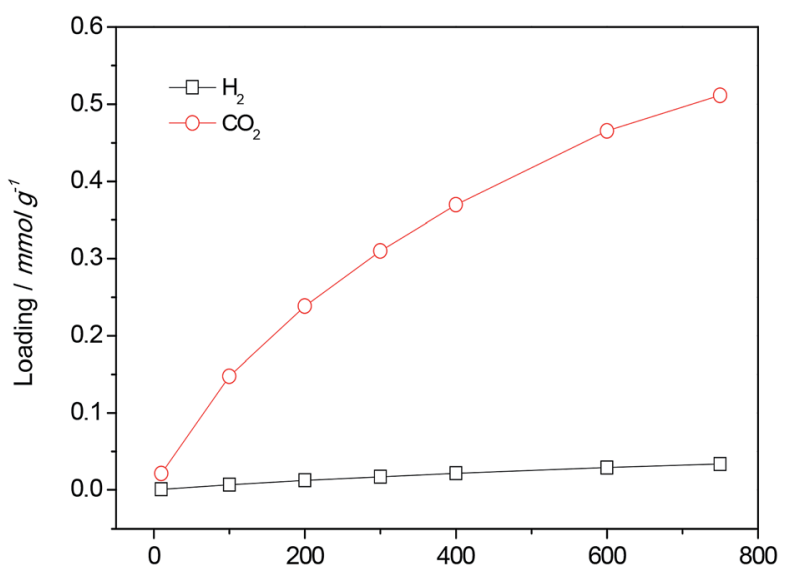

Fig. 4 Simulated mixed gas adsorption isotherms of equimolar $\mathrm{H}_{2} /$ $\mathrm{CO}_{2}$ mixtures at $25^{\circ} \mathrm{C}$ in the pressure range from 10 to 750 Torr. The pressure on the abscissa indicates the total pressure of the equimolar binary mixture. 

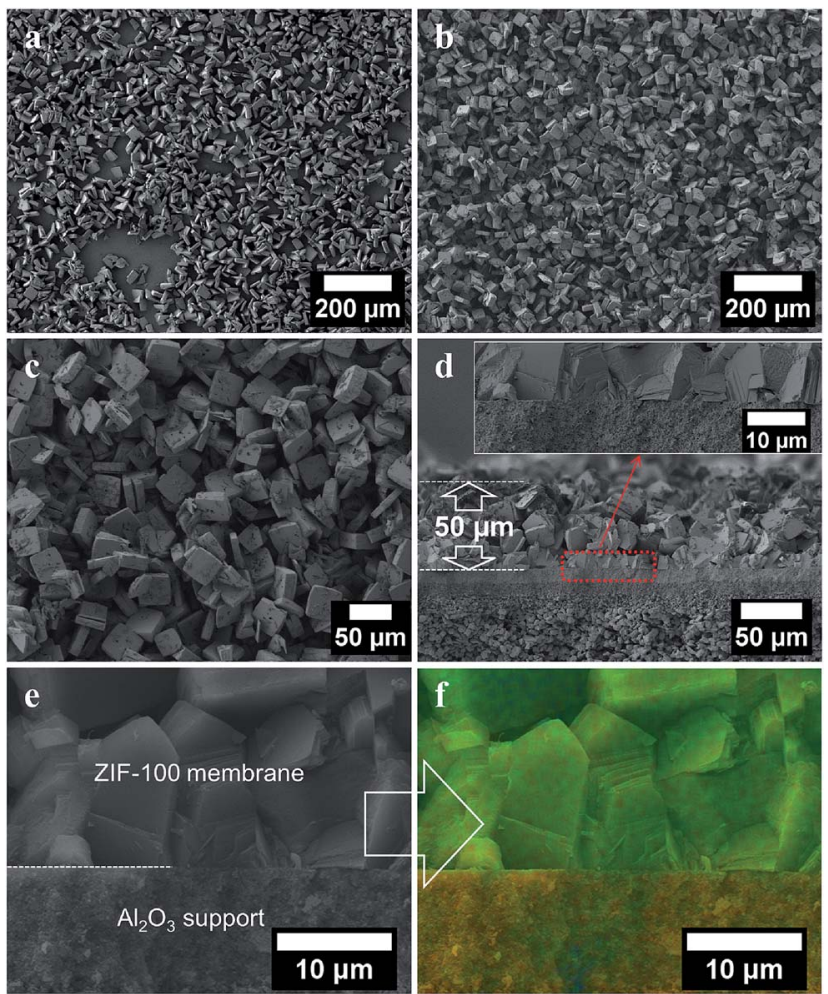

Fig. 5 SEM top views of (a) ZIF-100 membranes prepared on a PDAfree $\mathrm{Al}_{2} \mathrm{O}_{3}$ support and ( $b$ and $c$ ) on a PDA-modified support, as well as ( $d$ and e) the cross-sectional view of the ZIF-100 membrane with PDAmodification. The inset of (d) shows a magnified part of the ZIF-100 membrane at the interface support-ZIF-100 layer. (f) shows the EDXS mapping of the magnified cross-section (green: $\mathrm{Zn}$ and $\mathrm{Cl}$ as tracers for ZIF-100; orange: Al as the tracer for the support). The $K_{\alpha 1}$ transitions have been used.

can be employed ${ }^{38}$ as a simple and powerful strategy to improve the nucleation of MOFs and zeolites on the alumina support surface through the formation of strong covalent bonds with the MOF or zeolite crystals. ${ }^{\mathbf{3 8 - 4 0}}$ In the present work, therefore, we tried to prepare a dense ZIF-100 membrane on the premodified support with PDA. As shown in Fig. 5(b) and (c), a continuous ZIF-100 layer is formed on the PDA-modified supports. From the cross-sectional view shown in Fig. 5(d), it follows that big crystals are loosely packed on the top of the ZIF100 membranes due to sedimentation, but as we can see from the magnified part (inset in Fig. 5(d)), a thin and well-intergrown ZIF-100 zone is formed at the interface to the support, thus controlling the selectivity for gas separation. Fig. 5(f) shows the EDXS mapping of the cross-section of the ZIF-100 membrane near the support surface (Fig. 5(e)). A sharp transition can be seen between the ZIF-100 membrane ( $\mathrm{Zn}$ and $\mathrm{Cl}$ signals) and the alumina support (Al signal) which means that there was no infiltration of the synthesis solution into the support. Also the above mentioned well-intergrown ZIF-100 zone near the support can be seen in Fig. 5(f).

The XRD patterns of ZIF-100 membranes are compared with those of ZIF-100 powder in Fig. 6. The results show that all diffraction peaks of the ZIF-100 layer prepared on either PDA-

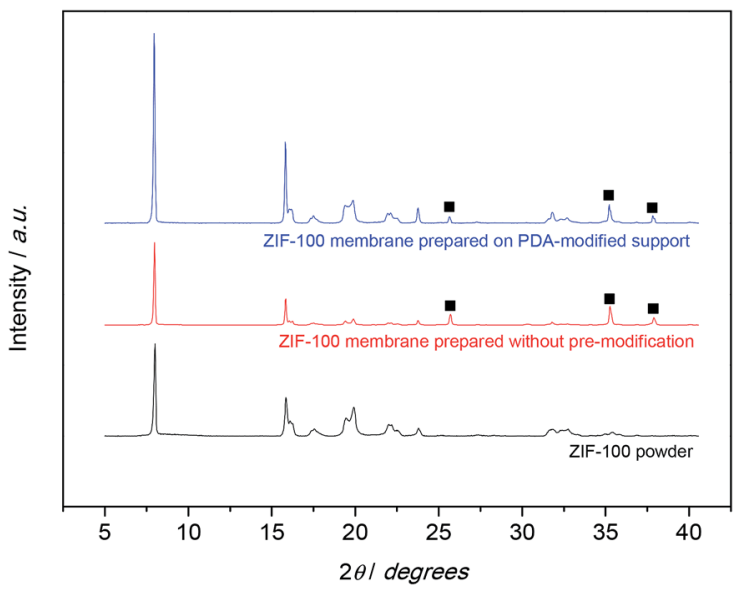

Fig. 6 XRD patterns of ZIF-100 membranes prepared on PDA-free and PDA-modified supports, compared with the XRD patterns of ZIF100 powder. ( $\mathbf{\square})$ for the $\mathrm{Al}_{2} \mathrm{O}_{3}$ support. Signals of $\mathrm{ZIF}-100$ crystals are not marked.

modified or bare supports match well with those of the ZIF-100 powder besides the $\alpha-\mathrm{Al}_{2} \mathrm{O}_{3}$ signals from the support, which indicates that the ZIF-100 membrane prepared on the PDAmodified substrate exhibits the pure ZIF-100 structure. Moreover, the XRD pattern of the PDA pre-modified ZIF-100 membrane shows higher ZIF-100 peak intensity compared to the membrane grown on the bare alumina support, since the ZIF-100 membrane grown on the PDA-based support is much denser and thicker.

\subsection{Single gas permeation and mixture gas separation}

It is worth noting that before the single gas permeation, the gas permeation performance of the mixed $\mathrm{H}_{2} / \mathrm{CO}_{2}$ gas pair on the PDA-modified alumina support was first measured and both the $\mathrm{H}_{2}$ permeance and $\mathrm{H}_{2} / \mathrm{CO}_{2}$ separation factor remained unchanged when compared to the permeance through the bare $\mathrm{Al}_{2} \mathrm{O}_{3}$ support, which indicates that the PDA-layer itself is not gas-selective.

The single gas permeances of $\mathrm{H}_{2}, \mathrm{CO}_{2}, \mathrm{~N}_{2}$ and $\mathrm{CH}_{4}$ through the ZIF-100 membrane prepared on the PDA-modified support at $25^{\circ} \mathrm{C}$ and 1 bar as a function of the kinetic diameter of the gas molecules are shown in Fig. 7, and the results in detail are summarized in Table 1. The inset gives the mixed separation factor for $\mathrm{H}_{2}$ over other gases from their equimolar mixtures. It can be seen that the single gas permeance of $\mathrm{H}_{2}$ at room temperature is $\sim 6.3 \times 10^{-8} \mathrm{~mol} \mathrm{~m}^{-2} \mathrm{~s}^{-1} \mathrm{~Pa}^{-1}$, and the single gas permeances through the ZIF-100 membrane follow the order $\mathrm{H}_{2}>\mathrm{N}_{2}>\mathrm{CH}_{4}>\mathrm{CO}_{2}$, which leads to the highest $\mathrm{H}_{2} / \mathrm{CO}_{2}$ separation factor of 72. Although $\mathrm{CO}_{2}$ has a smaller kinetic diameter than $\mathrm{N}_{2}$ and $\mathrm{CH}_{4}$, it was believed that the molecular sieving effect did not dominate the separation process, and the high $\mathrm{H}_{2} / \mathrm{CO}_{2}$ selectivity can be explained by the diffusivitysolubility model of gas permeation instead. As reported previously, ${ }^{29}$ only $\mathrm{CO}_{2}$ can be retained in the pore structure of ZIF-100 while other small gas molecules will easily permeate through the framework since ZIF-100 shows a strong adsorption of $\mathrm{CO}_{2}$ 


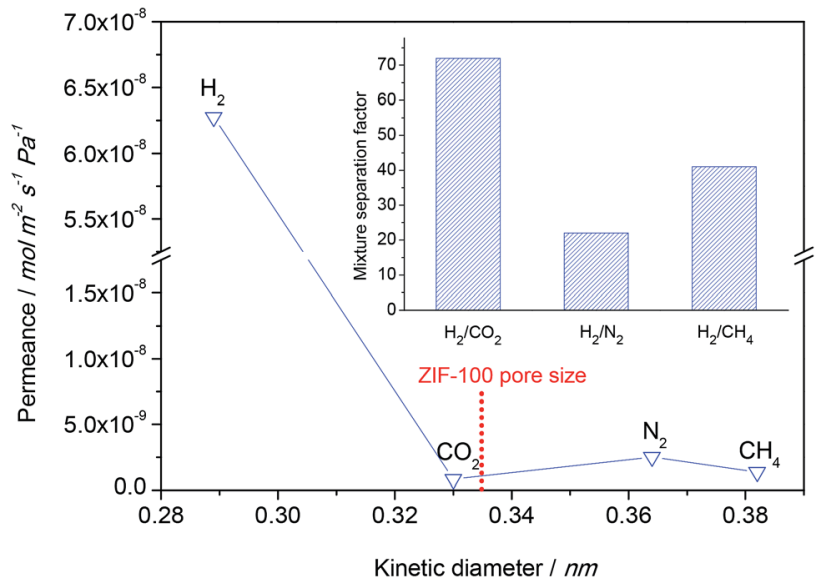

Fig. 7 Single gas permeances through the ZIF-100 membrane prepared by PDA-modification at $25^{\circ} \mathrm{C}$ and 1 bar as a function of the kinetic diameter of permeated gases. The inset shows the mixture separation factors for $\mathrm{H}_{2}$ over other gases from equimolar mixtures.

originating from the strong quadrupolar interactions of carbon with nitrogen atoms in the linkers of ZIF-100. The strong adsorption ability of $\mathrm{CO}_{2}$ has been confirmed by the simulation study, as shown in Section 3.1. The mobility of $\mathrm{CO}_{2}$ was retarded by this strong adsorption, while $\mathrm{H}_{2}$ can still pass through the pore network easily, leading to a high $\mathrm{H}_{2} / \mathrm{CO}_{2}$ selectivity. This experimental finding is similar to those reported on zeolite ${ }^{50-52}$ and MOF membranes. ${ }^{21,26,53-55}$

Fig. 8 shows the single gas permeance of $\mathrm{H}_{2}$ and $\mathrm{CO}_{2}$ as well as the mixture separation factors for equimolar $\mathrm{H}_{2} / \mathrm{CO}_{2}$ mixtures at 1 bar as a function of temperature from 25 to $150{ }^{\circ} \mathrm{C}$. It can be seen that the $\mathrm{H}_{2} / \mathrm{CO}_{2}$ separation factors reduce gradually with increasing temperature in a temperature window of 25 to $100{ }^{\circ} \mathrm{C}$, and then only slightly decrease when the temperature is higher than $100{ }^{\circ} \mathrm{C}$. This trend can be explained by the interplay of adsorption and diffusion of $\mathrm{H}_{2}$ and $\mathrm{CO}_{2}$ in the pore structure of ZIF-100. At low temperatures, a large amount of $\mathrm{CO}_{2}$ molecules is adsorbed in the ZIF-100 pores and only the highly mobile $\mathrm{H}_{2}$ can diffuse through the membrane. As the temperature increases, less $\mathrm{CO}_{2}$ becomes adsorbed and both $\mathrm{H}_{2}$ and $\mathrm{CO}_{2}$ can diffuse more easily in the resulting free volume, which leads to an enhancement of both $\mathrm{H}_{2}$ and $\mathrm{CO}_{2}$ permeance. Since the $\mathrm{CO}_{2}$ permeance increases faster than the

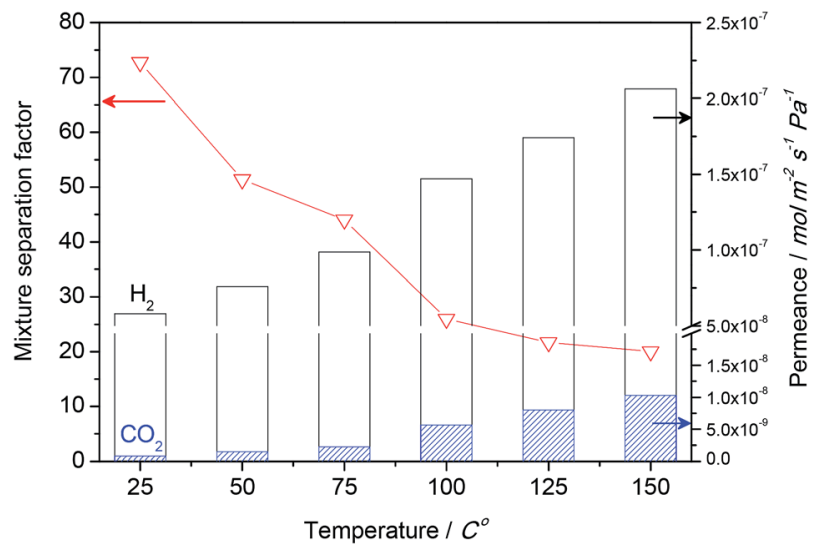

Fig. 8 Single gas permeances of $\mathrm{H}_{2}$ and $\mathrm{CO}_{2}$ and mixture separation factors for $\mathrm{H}_{2} / \mathrm{CO}_{2}$ from an equimolar mixture on the $\mathrm{ZIF}-100$ membrane prepared by PDA-modification at 1 bar as a function of temperature.

$\mathrm{H}_{2}$ one, the $\mathrm{H}_{2} / \mathrm{CO}_{2}$ selectivity decreases with increasing temperature. After the temperature reached $100{ }^{\circ} \mathrm{C}$, the effect of the $\mathrm{CO}_{2}$ adsorption is substantially reduced and the gas separation behaviour of ZIF-100 becomes dominated by the kinetic molecular sieving effect since the width of the pore apertures of ZIF-100 is in a similar size to $\mathrm{CO}_{2}$. However, because of the gate opening due to linker distortion, no sharp cut-off can be expected..$^{56-63}$ Further, the ZIF-100 membrane shows completely reversible separation behaviour between 25 and $150{ }^{\circ} \mathrm{C}$. The permeances measured during the cooling-down are consistent well with those during the heating-up.

In addition, the ZIF-100 membrane can maintain its high $\mathrm{H}_{2} /$ $\mathrm{CO}_{2}$ selectivity when the feed pressure increases. As shown in Fig. 9, when the $\mathrm{H}_{2}$ and $\mathrm{CO}_{2}$ partial pressure increased from 0.5 to 2 bar (corresponding to a change in the total feed pressure from 1 to 4 bar), the $\mathrm{H}_{2} / \mathrm{CO}_{2}$ separation factor reduces only slightly which is a direct proof that the membrane does not contain macroscopic defects.

Moreover, it was also found that the synthesis method with pre-modification of the $\alpha$-alumina supports by PDA can contribute to a higher reproducibility of ZIF-100 membrane preparation, as shown in Table 2. The gas separation performances of 5 different membranes prepared by the same method were tested and the mixture separation factors of $\mathrm{H}_{2} / \mathrm{CO}_{2}$ do not scatter more than $\pm 10 \%$.

Table 1 Single and mixed gas (with $1: 1$ binary mixtures) permeances as well as the ideal and mixture separation factors on the ZIF-100 membrane prepared by pre-modification with PDA at $25^{\circ} \mathrm{C}$ and 1 bar

Separation performance of the ZIF-100 membrane

Single gas $\quad$ Mixed gases

Permeances $(i) \quad$ Permeances $(j) \quad$ Ideal separation Permeances $(i) \quad$ Permeances $(j) \quad$ Mixture separation $\operatorname{Gas}_{i j j} \quad$ Knudsen constant $\left(\mathrm{mol} \mathrm{m} \mathrm{s}^{-2} \mathrm{sa}^{-1}\right)\left(\mathrm{mol} \mathrm{m}^{-2} \mathrm{~s}^{-1} \mathrm{~Pa}^{-1}\right)$ factor $\quad\left(\mathrm{mol} \mathrm{m}^{-2} \mathrm{~s}^{-1} \mathrm{~Pa}^{-1}\right)\left(\mathrm{mol} \mathrm{m}^{-2} \mathrm{~s}^{-1} \mathrm{~Pa}^{-1}\right)$ factor $(\alpha)$

$\begin{array}{lllllll}\mathrm{H}_{2} / \mathrm{CO}_{2} & 4.7 & 6.3 \times 10^{-8} & 8.1 \times 10^{-10} & 77 & 5.8 \times 10^{-8} & 8.0 \times 10^{-10} \\ \mathrm{H}_{2} / \mathrm{N}_{2} & 3.7 & & 2.5 \times 10^{-9} & 25 & 6.2 \times 10^{-8} & 2.7 \times 10^{-9} \\ \mathrm{H}_{2} / \mathrm{CH}_{4} 2.8 & & 1.4 \times 10^{-9} & 46 & 5.8 \times 10^{-8} & 1.4 \times 10^{-9} & 41\end{array}$




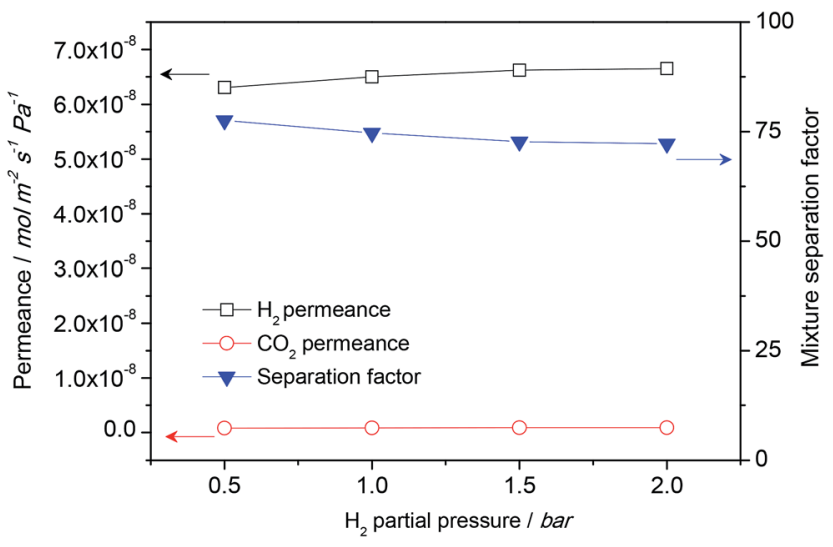

Fig. $9 \mathrm{H}_{2}$ and $\mathrm{CO}_{2}$ permeances and $\mathrm{H}_{2} / \mathrm{CO}_{2}$ mixed gas selectivity of the ZIF-100 membrane prepared by PDA-modification as a function of hydrogen partial pressure in the feed from equimolar mixtures at room temperature. Permeate pressure was kept constant at 1 bar.

Table 2 Single gas permeances of $\mathrm{H}_{2}$ and $\mathrm{CO}_{2}$ and mixture separation factors of $\mathrm{H}_{2} / \mathrm{CO}_{2}$ from equimolar mixtures at room temperature and 1 bar feed/1 bar permeate of 5 tested ZIF-100 membranes showing the reproducibility of membrane preparation and testing

\begin{tabular}{llll}
\hline & $\begin{array}{l}\mathrm{H}_{2} \text { permeance } \\
\left(\mathrm{mol} \mathrm{m}^{-2} \mathrm{~s}^{-1} \mathrm{~Pa}^{-1}\right)\end{array}$ & $\begin{array}{l}\mathrm{CO}_{2} \text { permeance } \\
\left(\mathrm{mol} \mathrm{m}{ }^{-2} \mathrm{~s}^{-1} \mathrm{~Pa}^{-1}\right)\end{array}$ & $\begin{array}{l}\text { Mixture separation factor } \\
\mathrm{H}_{2} / \mathrm{CO}_{2}\end{array}$ \\
\hline 1 & $6.3 \times 10^{-8}$ & $8.1 \times 10^{-10}$ & 72 \\
2 & $6.5 \times 10^{-8}$ & $8.0 \times 10^{-10}$ & 76 \\
3 & $6.1 \times 10^{-8}$ & $7.9 \times 10^{-10}$ & 68 \\
4 & $6.6 \times 10^{-8}$ & $8.1 \times 10^{-10}$ & 75 \\
5 & $5.8 \times 10^{-8}$ & $7.8 \times 10^{-10}$ & 70
\end{tabular}

\section{Conclusions}

Dense and phase-pure ZIF-100 membranes have been prepared on the PDA-modified alumina support at $120^{\circ} \mathrm{C}$ for $48 \mathrm{~h}$. After the pre-modification with PDA, the ZIF-100 nutrients were attached to the support surface through the formation of covalent chemical bonds. The mixture separation factors of $\mathrm{H}_{2} / \mathrm{CO}_{2}, \mathrm{H}_{2} / \mathrm{N}_{2}$ and $\mathrm{H}_{2} / \mathrm{CH}_{4}$ through the PDAbased ZIF-100 membrane were 72,22 and 41 at room temperature and 1 bar. The high $\mathrm{H}_{2} / \mathrm{CO}_{2}$ selectivity is ascribed to the high $\mathrm{CO}_{2}$ uptake behaviour of ZIF-100 and a small window aperture of $3.35 \AA$.

\section{Acknowledgements}

Nanyi Wang is grateful for the financial support by EU CARENA (FP7-NMP-2010-LARGE-4, Nr. 263007), and the Chinese Academy of Science Visiting Professorship for Senior International Scientists (Grant no. 2013T1G0047) is acknowledged. Zhiwei Qiao acknowledges support by China Postdoctoral Science Foundation (No. 2014M560663) and the Fundamental Research Funds for the Central Universities (No. 2014ZB0012).

\section{Notes and references}

1 S. Dunn, Int. J. Hydrogen Energy, 2002, 27, 235.

2 J. R. Rostrup-Nielsen and T. Rostrup-Nielsen, CATTECH, 2002, 6, 150.

3 A. A. Olagire, Energy, 2010, 35, 2610.

4 A. J. Brown, N. A. Brunelli, K. Eum, F. Rashidi, J. R. Johnson, W. J. Koros, C. W. Jones and S. Nair, Science, 2014, 345, 72.

5 M. Hong, S. Li, J. L. Falconer and R. D. Noble, J. Membr. Sci., 2008, 307, 277.

6 F. Gallucci, E. Fernandez, P. Corengia and M. S. Annaland, Chem. Eng. Sci., 2013, 92, 40.

7 S. Uemiya, T. Matsuda and E. Kikuchi, J. Membr. Sci., 1991, 56, 315.

8 R. M. de Vos and H. Verweij, Science, 1998, 279, 1710.

9 M. B. Shiflett and H. C. Foley, Science, 1999, 285, 1902.

10 H. Li, M. Eddaoudi, M. O. Keeffe and O. M. Yaghi, Nature, 1999, 402, 276.

11 M. Dincâ, A. F. Yu and J. R. Long, J. Am. Chem. Soc., 2006, 128, 8904.

12 S. Hermes, F. Schroder, R. Chelmowski, C. Woll and R. A. Fischer, J. Am. Chem. Soc., 2005, 127, 13744.

13 R. Ranjan and M. Tsapatsis, Chem. Mater., 2009, 21, 4920.

14 A. Bétard, H. Bux, S. Henke, D. Zacher, J. Caro and R. A. Fischer, Microporous Mesoporous Mater., 2012, 150, 76.

15 Y. Yoo, Z. Lai and H. K. Jeong, Microporous Mesoporous Mater., 2009, 123, 100.

16 T. Rodenas, M. van Dalen, E. García-Pérez, P. Serra-Crespo, B. Zornoza, F. Kapteijn and J. Gascon, Adv. Funct. Mater., 2014, 24, 249.

17 F. Cacho-Bailo, B. Seoane, C. Téllez and J. Coronas, J. Membr. Sci., 2014, 464, 119.

18 R. Banerjee, A. Phan, B. Wang, C. Knobler, H. Furukawa, M. O'Keeffe and O. M. Yaghi, Science, 2008, 319, 939.

19 A. Phan, C. J. Doonan, F. J. Uribe-romo, C. B. Knobler, M. O'Keeffe and O. M. Yaghi, Acc. Chem. Res., 2010, 43, 58.

20 Y. Li, F. Liang, H. Bux, A. Feldhoff, W. Yang and J. Caro, Angew. Chem., 2010, 122, 558; Angew. Chem., Int. Ed., 2010, 49, 548.

21 A. Huang, H. Bux, F. Steinbach and J. Caro, Angew. Chem., Int. Ed., 2010, 49, 4958.

22 H. Bux, F. Liang, Y. Li, J. Cravillon, M. Wiebcke and J. Caro, J. Am. Chem. Soc., 2009, 131, 16000.

23 H. Bux, A. Feldhoff, J. Cravillon, M. Wiebcke, Y. Li and J. Caro, Chem. Mater., 2011, 23, 2262.

24 Y. Pan and Z. Lai, Chem. Commun., 2011, 47, 10275.

25 A. Huang, W. Dou and J. Caro, J. Am. Chem. Soc., 2010, 132, 15562.

26 A. Huang and J. Caro, Angew. Chem., Int. Ed., 2011, 50, 4979. 27 A. Huang, N. Wang, C. Kong and J. Caro, Angew. Chem., Int. Ed., 2012, 51, 10551.

28 A. Huang, Y. Chen, N. Wang, Z. Hu, J. Jiang and J. Caro, Chem. Commun., 2012, 48, 10981.

29 B. Wang, A. P. Côté, H. Furukawa, M. O'Keeffe and O. M. Yaghi, Nature, 2008, 453, 207. 
30 S. Bourrelly, P. L. Llewellyn, C. Serre, F. Millange, T. Loiseau and G. Férey, J. Am. Chem. Soc., 2009, 131, 6326.

31 L. Valenzano, B. Civalleri, S. Chavan, G. T. Palomino, C. O. Areán and S. Bordiga, J. Phys. Chem. C, 2010, 114, 11185.

32 S. Sircar, T. C. Golden and M. B. Rao, Carbon, 1996, 34, 1.

33 M. Prakash, N. Sakhavand and R. Shahsavari, J. Phys. Chem. C, 2013, 117, 24407.

34 H. Lee, S. M. Dellatore, W. M. Miller and P. B. Messersmith, Science, 2007, 318, 426.

35 H. Lee, J. Rho and P. B. Messersmith, Adv. Mater., 2009, 21, 431.

36 J. Ryu, S. H. Ku, H. Lee and C. B. Park, Adv. Funct. Mater., 2010, 20, 2132.

37 D. Ling, W. Park, Y. I. Park, N. Lee, F. Li, C. Song, S. Yang, S. H. Choi, K. Na and T. Hyeon, Angew. Chem., Int. Ed., 2011, 50, 11360.

38 Q. Liu, N. Wang, J. Caro and A. Huang, J. Am. Chem. Soc., 2013, 135, 17679.

39 A. Huang, Q. Liu, N. Wang and J. Caro, J. Mater. Chem. A, 2014, 2, 8246.

40 C. Yuan, Q. Liu, H. Chen and A. Huang, RSC Adv., 2014, 4, 41982.

41 RASPA 1.0., ed. D. Dubbeldam, S. Calero, D. E. Ellis and R. Q. Snurr, Northwestern University, Evanston, IL, 2008.

42 S. L. Mayo, B. D. Olafson and W. A. Goddard, J. Phys. Chem., 1990, 94(26), 8897.

43 A. K. Rappe, C. J. Casewit, K. S. Colwell, W. A. Goddard III and W. M. Skiff, J. Am. Chem. Soc., 1992, 114(25), 10024.

44 C. M. Breneman and K. B. Wiberg, J. Comput. Chem., 1990, 11(3), 361.

45 C. Lee, W. Yang and R. G. Parr, Phys. Rev. B: Condens. Matter Mater. Phys., 1988, 37(2), 785.

46 A. D. Becke, J. Chem. Phys., 1993, 98, 5648.

47 M. G. Martin and J. I. Siepmann, J. Phys. Chem. B, 1998, 102(14), 2569.
48 C. S. Murthy, K. Singer, M. L. Klein and I. R. McDonald, Mol. Phys., 1980, 41(6), 1387.

49 P. P. Ewald, Ann. Phys., 1921, 64(3), 253.

50 A. Huang, N. Wang and J. Caro, J. Membr. Sci., 2012, 389, 272.

51 A. Huang and J. Caro, J. Mater. Chem., 2011, 21, 11424.

52 N. Wang, Y. Liu, A. Huang and J. Caro, Microporous Mesoporous Mater., 2014, 192, 8.

53 Y. Li, F. Liang, H. Bux, A. Feldhoff, W. Yang and J. Caro, Angew. Chem., Int. Ed., 2010, 49, 548.

54 A. Huang, Y. Chen, N. Wang, Z. Hu, J. Jiang and J. Caro, Chem. Commun., 2012, 48, 10981.

55 N. Wang, A. Mundstock, Y. Liu, A. Huang and J. Caro, Chem. Eng. Sci., DOI: 10.1016/j.ces.2014.10.037

56 C. Gücüyener, J. van den Bergh, J. Gascon and F. Kapteijn, J. Am. Chem. Soc., 2010, 132, 17704.

57 D. Fairen-Jimenez, S. A. Moggach, M. T. Wharmby, P. A. Wright, S. Parsons and T. Düren, J. Am. Chem. Soc., 2001, 133, 8900.

58 S. A. Moggach, T. D. Bennett and A. K. Cheetham, Angew. Chem., 2009, 121, 7221.

59 T. Chokbunpiam, R. Chanajaree, T. Remsungnen, O. Saengsawang, S. Fritzsche, C. Chmelik, J. Caro, W. Janke and S. Hannongbua, Microporous Mesoporous Mater., 2014, 187, 1.

60 S. Aguado, G. Bergeret, M. P. Titus, V. Moizan, C. NietoDraghi, N. Bats and D. Farrusseng, New J. Chem., 2011, 35, 546.

61 J. van den Bergh, C. Gücüyener, E. A. Pidko, E. J. M. Hensen, J. Gascon and F. Kapteijn, Chem.-Eur. J., 2011, 17, 8832.

62 D. L. Chen, N. Wang, F. F. Wang, J. Xie, Y. Zhong, W. Zhu, J. K. Johnson and R. Krishna, J. Phys. Chem. C, 2014, 118, 17831.

63 C. O. Ania, E. García-Pérez, M. Haro, J. J. Gutiérrez-Sevillano, T. Valdés-Solís, J. B. Parra and S. Calero, J. Phys. Chem. Lett., 2012, 3, 1159. 